\title{
CÁLCULO Y EMOCIONES EN PEDRO PÁRAMO
}

\author{
CALCULATION AND EMOTIONS IN PEDRO PÁRAMO
}

\author{
Alberto Vital Díaz \\ Universidad Nacional Autónoma de México. Ciudad de México, México \\ albertovitalo4@yahoo.com.mx
}

\begin{abstract}
Resumen: Si bien los textos literarios son mundos posibles, autónomos y autosuficientes, están anclados de tal modo en la realidad que arrojan luz sobre la vida misma mediante los discursos ficticios que permiten el esclarecimiento de aspectos subjetivos y llenan déficits emocionales. Del mismo modo, los personajes irradian fulgores que nos permiten la comprensión de las personas, de nuestras experiencias y vivencias, e incluso de nuestras decisiones y acciones. Este artículo tiene como hipótesis que el cálculo y las emociones se mezclan de modos diferentes en cada persona, en cada situación y en cada interacción social. Pedro Páramo ofrece, mediante la interacción de sus personajes en distintos contextos -en los que incluso se atreven a medir o cuantificar las emociones-, una gran variedad de ejemplos que lo demuestran, en los que influyen condiciones concretas, tanto económicas como políticas y sociales. Pedro Páramo es un paradigma de cuán destructivas pueden resultar emociones como el amor, la ilusión, el desconsuelo, el temor, la frustración, la ambición, entre otras, todas ellas afincadas en complejos sistemas de creencias y hábitos; por lo demás, las emociones se vinculan con actitudes proposicionales, con ideas, prejuicios, argumentaciones y visiones del mundo.
\end{abstract}

Palabras clave: Cálculo, emociones, déficit, racionalidad instrumental, diálogo, $P e$ dro Páramo, actitudes proposicionales.

\begin{abstract}
While literary texts may be regarded as possible, autonomous and selfsufficient worlds, they are somehow anchored into reality and life itself that allow us both to clarify subjective issues and fulfill emotional deficits. In a similar way, fictional characters help us to understand how other people's minds work as well as our own life experiences and even our own acts and decisions. This paper stands that calculations and emotions are mixed up differently in each person, each situation and each social interaction. Juan Rulfo's novel Pedro Páramo gives us a wide variety of examples showing that kind of mixture, notoriously seen in the characters that dare to balance their emotions regarding their specific economic, political and social conditions. Pedro Páramo could be seen as a paradigm of how destructive might be emotions like love, illusion, grief, fear, frustration, ambition, embedded in complex systems of ha-
\end{abstract}


bits and beliefs like the ones that ruled in Mexico's mid-2oth Century. Not to mention that emotions are undoubtedly linked to propositional attitudes, ideas, prejudices, arguments and world's visions.

Keywords: Calculation, emotions, deficit, instrumental racionality, dialogue, Pedro Páramo, propositional attitudes.

Recibido: 16.06.2017. Aceptado: 08.10.2017

$L$ AS SOMBRAS del mañana. La dimensión subjetiva de la política, de Norbert Lechner (2002), expone cómo el racionalismo instrumentalista ha desplazado la subjetividad en los análisis de los procesos políticos, sobre todo a partir del siglo XVIII ${ }^{1}$. Ello ha sido así pese a que las evidencias nos enseñan que individuos específicos ponen su sello en la historia humana: tal es el caso, entre muchos otros, de Adolfo Hitler y José Stalin, cuyo narcisismo compulsivo, sin diques ni contrapesos, arrastró hasta la muerte a miles, decenas de miles, cientos de miles, millones de seres vivos.

Si el racionalismo instrumentalista se asume como el discurso hegemónico más o menos explícito, más o menos implícito en numerosas prácticas cotidianas, entonces cae en el supuesto de que los textos de ficción (incluidos por cierto el cine, las radionovelas, las telenovelas y las series televisivas) vienen a completar aquellos "déficits" que provocan todos los "modelos de explicación del mundo", especialmente en aquellos modelos que, por ser hegemónicos o pretender incluso erigirse en los únicos posibles, corren un mayor riesgo de sólo explicar el todo por la parte, un todo demasiado grande, una parte demasiado atenida a unos cuantos ejemplos, historias, argumentos, narrativas ${ }^{2}$.

\footnotetext{
1 "La narrativa acerca de la realidad social tiene un trasfondo histórico que conviene recordar. Ella toma cuerpo en el siglo xviII, cuando se empieza a concebir la naturaleza como algo eterno e inmutable. [...] A partir de los hechos, el método inductivo y la cuantificación de los fenómenos permitirían establecer relaciones causales. [...] Desde entonces será tarea del análisis social traducir las causalidades observadas en una acción instrumental medio-fin. / Este proceso crea no sólo la distinción por todos conocida entre la naturaleza y el ámbito de la acción social. Además, termina por asimilar la sociedad a la naturaleza. La antigua idea de un orden social, evaluado según normas morales, es sustituida por la concepción de un sistema abstracto e impersonal" "La des-subjetivación de la reflexión", en 2002: 16).

${ }^{2}$ A este último respecto, Hansberg (2001: 23) cita una advertencia metodológica o heurística de Wittgenstein: no "'nutrir [el] pensamiento sólo de un tipo de ejemplos' (In-
} 
Un "déficit" es justamente la insuficiencia en el esclarecimiento de los aspectos subjetivos, los intereses de los sujetos, los temas de las personas, entre ellos sobre todo las emociones en la amplia diversidad de las mismas. Ello contribuiría a explicar (al menos en parte) la persistencia de los discursos ficticios y la fuerte preferencia colectiva por dichos discursos: porque han llenado los vacíos emocionales, los déficits en expresiones específicas de los individuos concretos.

En este contexto no resulta por completo improbable que el presente análisis ejemplifique determinados planteamientos que realizan Hansberg (2001, 1996) y Nussbaum (2008). Esta contribución se basaría en la hipótesis de que si bien los textos literarios son mundos posibles en sí mismos, autónomos y autosuficientes, aun así están construidos de tal modo que siempre podrán arrojar una luz quizá oblicua, si se quiere indirecta y mediada, hacia el mundo de la vida ${ }^{3}$ Y es así como los personajes irradian fulgores de comprensión hacia las personas, esto es, hacia nuestras experiencias y vivencias, nuestras decisiones y acciones.

Pedro Páramo parece útil para este empeño. Uno de los protagonistas, Juan Preciado, muere de miedo (la emoción cuyo análisis sirve de modelo en La diversidad de las emociones). Los otros dos mueren de pasiones no resueltas y no esclarecidas (Susana) y de soledad y frustración tampoco esclarecida (Pedro). Por lo pronto ha de decirse que la trama de la novela describe paso a paso, con fineza, cómo un individuo normal, cooperativo y atento, va desconcertándose y descoyuntándose hasta que se le revientan "las cuerdas", como él mismo dice: Juan. También describe los procesos de

vestigaciones filosóficas: 593)”. La teoría de la recepción, en especial Wolfgang Iser, se ha ocupado de la relación entre dichos "modelos de explicación del mundo", como las Weltanschaungen, y la literatura en el marco de los requerimientos intelectuales, emocionales y sociales de los lectores.

${ }^{3}$ Antonio Garrido Domínguez (2007) ofrece una apretada exposición de las cercanías y diferencias entre el mundo de la vida y los mundos posibles ("El relato literario y la noción de mundo posible”, en 2007: 29-33). Por su parte, Hansberg (2001: 26) destaca el valor de los textos literarios para la comprensión de diversos fenómenos y matices en las emociones: "Aunque es cierto que algunos de los problemas más importantes en relación con las emociones son propios de la filosofía, no hay que olvidar que son los escritores quienes describen con mayor vivacidad la riqueza de la experiencia emocional". Igualmente, escribe Bartra (2004: 65): "El neurofisiólogo mexicano José Luis Díaz ha intuido que, para explicar la conciencia tenemos, además de las herramientas de la neurociencia, las técnicas y teorías de la crítica literaria (El ábaco, la lira y la rosa. Las regiones del conocimiento, Fondo de Cultura Económica, México, 1997: 20)”. 
desmantelamiento emocional de Susana y de Pedro, al punto de que una novela escrita en fragmentos discontinuos, no cronológicos, encuentra una secreta continuidad en estos tres procesos, ellos sí lineales, de desmantelamiento no sólo del sistema emocional de cada uno de ellos, sino asimismo del correspondiente sistema de creencias y de proposiciones explicativas. De los tres, el único que tendrá acceso a un espacio-tiempo de aclaración será Juan Preciado, el menos apreciado de los tres. Ese espacio-tiempo no será un salón de clases, un auditorio, un agradable café, una tribuna, una casa de las Humanidades; no: será una tumba. Como dirá su compañera de tumba e interlocutora Dorotea la Cuarraca: ahora ya hay tiempo para pensar.

Igualmente, la novela entera tiene mucho de récit de paroles, pues no es otra cosa que un largo diálogo entre Dorotea y Juan en la tumba. Dentro de ese diálogo se recuperan muchos acontecimientos o eventos (de modo que Pedro Páramo también es un récit de événements, conforme a la ya clásica distinción de Gérard Genette). Por ejemplo, el pasaje que analizaré al final es un diálogo dentro de un diálogo dentro de un diálogo (Bartolomé-Pedro, Bartolomé-Susana, Dorotea-Juan), y ello no hace sino confirmar que el autor destinó mucho espacio en la novela para la argumentación y la exposición de emociones. De este modo (mediante el diálogo y más aun mediante el diálogo dentro del diálogo), se facilita aquello que Hansberg sintetiza como la "descripción de las actitudes proposicionales" (1996: 49-55). De hecho, la novela es una variada y diversificada descripción de actitudes proposicionales, donde convergen explicaciones y justificaciones de actos y de afectos y desafectos.

Pues bien, el destino de Pedro Páramo podría contribuir a que captáramos determinados matices en la confluencia -dentro de una misma persona- de la racionalidad asumida como cálculo político y económico y de una emoción específica, el sentimiento amoroso, perfectamente focalizada y asumida hasta sus últimos efectos.

Una hipótesis consistirá en suponer que el cálculo y las emociones se mezclan de modos diferentes en cada persona e incluso en cada situación

${ }^{4}$ Juan Rulfo, lector de Paul Valéry, acaso conoció aquella reflexión del Sócrates de Eupalinos o el arquitecto: la falta de un cuerpo exige a la mente seguir el pensamiento hasta sus últimas repercusiones. Más abajo se retoma este pasaje. 
e interacción de cada persona. Esos modos diferentes dejarían clasificarse en una taxonomía así sea inicial y provisional, que en las páginas siguientes apenas se apuntará 5 . Al mismo tiempo, no se hace aquí caso omiso de las condiciones concretas de las personas ni de los personajes, tanto económicas como políticas y sociales, pero se busca advertir si no será que la intervención de un individuo específico impone su sello a dichas condiciones colectivas e incluso las orienta al influir en el transcurso de las mismas. Tal influjo se produce mediante cálculos e intereses susceptibles de argumentarse y asimismo mediante experiencias anímicas, afectivas, acaso inconscientes en el momento de la acción y de cualquier manera afincadas en complejos sistemas de creencias y hábitos, todo ello en el marco de una ardua relación entre el individuo y su entorno, entre el yo y las concéntricas circunstancias invisibles y acaso en general imperceptibles ${ }^{6}$.

El personaje Pedro Páramo está construido sobre la base de una bipolaridad perfecta, tan perfecta que sería casi esquemática si no fuera por la sutileza con que el autor va dotando de verosimilitud y variedad de matices ambas mitades de la personalidad de este protagonista de su novela. De un lado, desde joven Pedro Páramo posee una capacidad de cálculo de tal modo depurada que es la base de la reconstrucción y casi más bien construcción de un imperio territorial digno de un encomendero del siglo xvi. De otro lado, él vuelca su vida afectiva en una sola persona a la manera paradigmática en que Romeo derrama la suya propia en Julieta y aun de modo más fuerte, pues Romeo al menos tiene otra novia al inicio de la tragedia y sólo la olvida porque acaba de conocer a la joven que marcará su destino.

La bipolaridad de Pedro Páramo casi estaría hablando de dos grandes "hemisferios" perfectamente separados; en las demás personas la separación casi nunca es perfecta y no podrá decirse que la razón nunca se mezcla con emociones o que las emociones nunca se mezclan con razones, juicios,

${ }^{5}$ En mi libro Los argumentos de los asesinos. Mecanismos de justificación en personajes de Juan Rulfo (2017) propongo una mínima clasificación inicial de tipos de argumentaciones en personajes literarios.

${ }^{6}$ Me baso en una aseveración de Wittgenstein citada por Hansberg (2001: 38-39): "'Cuando empezamos a creer algo, lo que creemos no es una única proposición, sino todo un sistema de proposiciones. (Se hace luz poco a poco sobre el conjunto)' (Wittgenstein, 1979: 141)". 
creencias en tanto que estados cognoscitivos7. En cambio, el completo éxito de Pedro Páramo como terrateniente y el fracaso asimismo completo ante Susana San Juan se explican en parte por una inusitada habilidad extrema para separar de modo tajante el cálculo, por una parte, y ese grupo de emociones que podemos reunir bajo el rubro de sentimiento amoroso o amor, por la otra.

También ha de decirse, en primer término, que el presente análisis reduce la racionalidad a una de sus manifestaciones: el cálculo. Se trata de una manifestación de la racionalidad tan característica, primaria y fundamental como el amor es una manifestación asimismo característica, primaria y fundamental de las emociones. La reducción de la racionalidad al cálculo se debe a que no hay un solo acto de la conciencia articulada, argumentativa y activa de Pedro Páramo que no sea un cálculo. De ese modo, es la propia estructura psíquica y mental de Pedro Páramo la que conduce a semejante reducción. En suma, el protagonista más famoso de la narrativa mexicana está construido mediante dos factores y ejemplos primarios e incluso primitivos y aun así siempre vigentes y universales y complejos de cada uno de esos dos hemisferios posibles de la condición humana: el cálculo y el amor. Más aun, el carácter trágico del personaje y de la novela obedece (al menos en parte) a esa bipolaridad que sería difícil descubrir con tanta pureza en una persona de carne y hueso, a menos que se tratara de un Adolfo Hitler o un José Stalin ${ }^{8}$.

${ }^{7}$ Según Hansberg (2001: 20-21): "Las teorías cognoscitivas actuales les conceden un papel fundamental a los estados cognoscitivos, generalmente a las creencias, y pretenden que son éstas las que nos permiten distinguir entre las diversas emociones. Sin embargo, sostener una teoría puramente cognitiva no sería lo adecuado para explicar las emociones. [...] Muchas de las teorías contemporáneas aceptan, entonces, combinaciones de estados cognoscitivos, actitudes evaluativas, deseos y otras actitudes proposicionales. Este trabajo se ubica dentro de este enfoque cognoscitivo y se centra principalmente en un examen de las relaciones de las emociones con actitudes proposicionales". En 1996, Hansberg apunta: "El de las emociones es un tema importante y muy complejo que ha despertado un renovado interés filosófico debido a que hemos dejado de concebirlas primordialmente como sentimientos o sensaciones que nos suceden, y frente a las cuales somos receptores pasivos, para concederles un componente racional que nos permita empezar a examinar las muy intrincadas relaciones que tienen con creencias, deseos y otras actitudes" (151).

${ }^{8}$ Esa pureza es uno de los ejemplos de que la relación entre la literatura y la vida nunca es inmediata y absoluta, pues si incluso los relatos testimoniales, los relatos de vida por ejemplo (incluidos los orales), son esquematizaciones de lo vivido, son selecciones, son articulaciones narrativas y discursivas, con tanta más razón lo serán los textos de ficción, y aun así a final de cuentas, por contraste y analogía (pero una analogía que no es asimilación 
A continuación se revisarán tres momentos de la novela, cruciales para ahondar en las afirmaciones precedentes:

-Miguel le dará muchos dolores de cabeza, don Pedro. Le gusta la pendencia.

-Déjalo moverse. Es apenas un niño. ¿Cuántos años cumplió? Tendrá diecisiete. ¿No, Fulgor?

-Puede que sí. Recuerdo que se lo trajeron recién, apenas ayer; pero es tan violento y vive tan de prisa que a veces se me figura que va jugando carreras con el tiempo. Acabará por perder, ya lo verá usted.

-Es todavía una criatura, Fulgor.

-Será lo que usted diga, don Pedro; pero esa mujer que vino ayer a llorar aquí, alegando que el hijo de usted le había matado a su marido, estaba de a tiro desconsolada. Yo sé medir el desconsuelo, don Pedro. Y esa mujer lo cargaba por kilos. Le ofrecí cincuenta hectolitros de maíz para que se olvidara del asunto; pero no los quiso. Entonces le prometí que corregiríamos el daño de algún modo. No se conformó.

-¿De quién se trataba?

-Es gente que no conozco.

-No tienes pues por qué apurarte, Fulgor. Esa gente no existe.

Llegó a las trojes y sintió el calor del maíz. Tomó en sus manos un puñado para ver si no lo había alcanzado el gorgojo. Midió la altura: "Rendirá -dijo-. En cuanto crezca el pasto ya no vamos a requerir darle maíz al ganado. Hay de sobra”.

De regreso miró el cielo lleno de nubes: "Tendremos agua para un buen rato”. Y se olvidó de todo lo demás (Rulfo, 2005a: 69).

indiferenciada), nos es dable comparar las experiencias y palabras de los personajes y las experiencias y palabras de las personas. De la comparación se desprende la posibilidad de que nos identifiquemos con tal o cual personaje. Jauss (1982) propone cinco tipos de identificación: asociativa (el receptor se incorpora al acto estético, como en el happening o en el alba medieval), admirativa (el receptor se asombra ante una vida perfecta, como ocurre en las hagiografías o en las vidas de grandes sabios: el héroe no padece un solo defecto), simpática (el héroe es imperfecto, como en la novela: es héroe en la vida cotidiana; el espectador siente piedad), catártica (la desgracia del héroe despierta piedad y terror; asimismo, el héroe cómico puede ser catártico, por lo que de catártica tiene la risa) e irónica (el héroe está prácticamente deconstruido en sus atributos positivos y aun así gana cierta complicidad de un receptor cuyo sistema de creencias ya de por sí está marcado por el escepticismo y por una actitud irónica y distanciada; el antihéroe entra en esta categoría) (244-292). 
Es de tal manera compleja la relación entre nuestras percepciones y emociones y los hechos circundantes que constantemente apelamos a las generalizaciones para estabilizar y normalizar esa relación. Las generalizaciones expresan nuestro dinámico sistema de creencias, que es a su vez una de las bases de nuestras actitudes proposicionales. Si no estoy equivocado, esas generalizaciones equivalen a aquello que para la fenomenología son los prejuicios, los juicios previos. Sea como fuere, aquí Pedro Páramo remata con una generalización: "Esa gente no existe". El intercambio verbal con su subordinado pasa de lo particular a lo general. Con dicha generalización queda saldada la discusión abierta por el subordinado (adviértase que el texto ya no dice qué respondió Fulgor: es irrelevante).

Fulgor Sedano ha puesto frente a su jefe un hecho irreversible que produce una emoción extrema en otra persona. Esa emoción es el desconsuelo. Fulgor incluso avanza en un terreno en el que quizá únicamente los psicólogos y los filósofos se atreverían a incursionar: la medición de las emociones; más aun, Fulgor prácticamente habla de la cuantificación de las emociones ${ }^{9}$. Se trata también de un recurso retórico: Fulgor está tratando de persuadir a Pedro Páramo de la gravedad del crimen cometido por Miguel Páramo. Pero el sistema de creencias del cacique es muy estable. No se modifica ni en situaciones límite. Como dice Wittgenstein, citado por Hansberg (2001: 23): empezamos a conocer un sistema al conocer una proposición ${ }^{10}$. (La gente que dice refranes, como Sancho Panza o como el padre en "Paso del Norte", vuelca en el plano del discurso explícito aquellas síntesis de determinados sistemas de creencias, ya codificados en cápsulas de sabiduría popular; existen otras creencias que no son refranes ni mucho menos, pero que flotan en el ambiente como síntesis de toda una forma de pensar. Pedro Páramo es parco y tiende a expresar sus concepciones más hondas y lo hace con crudeza y puntualidad.) Y podemos inferir otras

\footnotetext{
${ }^{9}$ Aun así, escribe Bartra (2007: 24): "Podríamos contemplar, plastificadas, nuestras tripas y nuestras venas enganchadas a un sistema portátil y prótesis impulsadas por sistemas cibernéticos programados. / Esto ocurre en los ciborgs de la ciencia-ficción y en los experimentos realizados en primates, los cuales, gracias a un electrodo implantado, han logrado controlar mentalmente una conexión cerebro-máquina para mover a distancia un brazo-robot. En cambio, estamos acostumbrados a estar rodeados de prótesis que nos ayudan a memorizar, a calcular e incluso a codificar nuestras emociones".

${ }^{10}$ Véase arriba nota 2.
} 
proposiciones que Pedro Páramo no dice y que son fundamentales en su sistema de creencias: "Esa gente me estorba", "Esa gente debe morir". Estas proto-proposiciones se deslizan indirectamente en su habla. Por eso es más significativo que en este pasaje sí exprese su proto-proposición: "Esa gente no existe".

Podría decirse que los últimos setenta años de la humanidad (con base en discusiones centenarias e incluso milenarias) han sido un esfuerzo mundial para que nadie, en situación de poder, pueda decir: "Esa gente no existe”. Por supuesto, al decirse eso también se está diciendo (sobre todo se está diciendo) que no se respeta en absoluto ni el sistema de creencias ni la totalidad de las proposiciones y aserciones emitidas por esa persona.

A la vez, este parlamento de Pedro Páramo comprueba que también en el ámbito de las emociones existe el ejercicio de la mediación: se media en un conflicto. Fulgor es un mediador entre Pedro Páramo y la viuda anónima. De hecho, abundan los ejemplos literarios cuyo trasfondo es una mediación en conflictos provocados por emociones incontroladas, desde el odio hasta la envidia.

Por supuesto, el conflicto en el pasaje citado desborda la esfera de las emociones y de los afectos: el asesinato de un esposo, esto es, de una parte constitutiva en una estructura familiar. Hoy la investigación universitaria retoma con fuerza el tema de la familia como un núcleo estructurante de la convivencia y, entre otros puntos, de los derechos humanos ${ }^{11}$. Resulta obvio que las emociones y las argumentaciones en torno a las emociones son fundamentales en la convivencia dentro de la familia. Pues bien, la narrativa de Rulfo tiene como una característica la ruptura de las estructuras familiares, sobre todo a causa de la violencia. Las estructuras sociales están asimismo rotas o son inexistentes. Por lo tanto, las emociones entre los personajes de Rulfo nunca pueden producirse en un horizonte de valores y de prácticas saludables; tampoco cuentan con mediaciones adecuadas y con mediadores más preparados y más exitosos que Fulgor Sedano. Carecen de un factor decisivo: ni más ni menos que de la base, la plataforma de

\footnotetext{
${ }^{11}$ José del Val ha trabajado la familia como concepto aglutinante tanto de los actores como de los derechos de dichos actores: mujer, niño, adulto mayor, principalmente (Del Val, palabras pronunciadas en la Inauguración del 1er. Simposio Miradas Contemporáneas a la familia, 2 diciembre 2015).
} 
todos esos estados de ánimo, de esos afectos, sensaciones y sentimientos que contribuyen a construir una convivencia justa y estable.

¿Pero cuál es la causa primera de semejante carencia? Desde luego, se puede aportar una respuesta en lo general: los hechos violentos son esa causa primera. La obra va proporcionando matices cruciales a esta generalización: aquí por ejemplo no hay emoción alguna en Pedro Páramo. No sólo eso: argumenta de tal modo que tampoco Fulgor, su subordinado, tiene derecho a sentir una emoción que de algún modo ayude a restituirle algo a la mujer, ya que ella no ha aceptado una transacción comercial que prácticamente hubiera convertido en mercancía a su esposo muerto. Por eso al final Fulgor vuelve al contacto con el maíz, al cálculo agrícola y comercial y al olvido de lo anterior: la mujer se queda sin mediador alguno, y su tragedia no alcanza ni siquiera la recompensa mínima de los cincuenta hectolitros de maíz ofrecidos al principio ${ }^{12}$.

La práctica de ofrecer materia como restitución de vida no es rara en Pedro Páramo. Ya otras veces se ensaya la cosificación de las emociones, la cuantificación de las conmociones, con el propósito de restituir un daño por la vía comercial, a falta de un aparato de justicia. De hecho, el abogado Gerardo degrada su profesión al punto de ponerla al servicio de las compensaciones monetarias como "restituciones" de daños en realidad irrever-

${ }^{12}$ La situación en Rulfo es de tal modo anómala por la violencia y por la falta de instituciones mediadoras que cuando el padre Rentería va a asistir a Susana San Juan, esto es, a mediar entre ella y Dios, termina siendo ella quien se percata del sufrimiento del padre y quien trata de ayudarlo: "-¿Eres tú, padre? / -Soy tu padre, hija mía. / Entreabre los ojos. Mira como si cruzara sus cabellos una sombra sobre el techo, con la cabeza encima de su cara. Y la figura borrosa de aquí enfrente, detrás de la lluvia de sus pestañas. Una luz difusa; una luz en el lugar del corazón, en forma de corazón pequeño que palpita como llama parpadeante. 'Se te está muriendo de pena el corazón - piensa-. Ya sé que vienes a contarme que murió Florencio; pero eso ya lo sé. No te aflijas por los demás; no te apures por mí. Yo tengo guardado mi dolor en un lugar seguro. No dejes que se te apague el corazón.' / Enderezó el cuerpo y lo arrastró hasta donde estaba el padre Rentería. / -iDéjame consolarte con mi desconsuelo! -dijo, protegiendo la llama de la vela con sus manos" (Rulfo, 2005a: 98). La palabra es, por lo demás, la gran mediadora o el gran instrumento de mediación. Aquí fracasa porque ella capta la esencia del ánimo del sacerdote, pero sólo puede transmitir una frase enigmática: “-iDéjame que te consuele con mi desconsuelo!” La exclamación tiene más de una lectura: consolar desde la conciencia desde la falta de consuelo, consolar desde lo más bajo de una emoción, consolar desde el otro extremo de una emoción. En The Taming the Shrew, de Shakespeare (1996: 333), hay una frase equivalente, de raíz acaso barroca: "BIANCA / Sister, content you in my discontent". Las traducciones no suelen captar la urgencia de mantener la misma palabra en dos vertientes. 
sibles, pues se producen en dos esferas muy diferentes y no equiparables (la muerte violenta frente al dinero):

Se quedó meditando. La cabeza caída. Oía el tintineo de los pesos sobre el escritorio donde Pedro Páramo contaba el dinero. Se acordaba de don Lucas, que siempre le quedó a deber sus honorarios. De don Pedro, que hizo cuenta nueva. De Miguel su hijo: icuántos bochornos le había dado ese muchacho!

Lo libró de la cárcel cuando menos unas quince veces, cuando no hayan sido más. Y el asesinato que cometió con aquel hombre, ¿cómo se apellidaba? Rentería, eso es. El muerto llamado Rentería, al que le pusieron una pistola en la mano. Lo asustado que estaba el Miguelito, aunque después le diera risa. Eso nomás, ¿̇cuánto le hubiera costado a don Pedro si las cosas hubieran ido hasta allá, hasta lo legal? Y lo de las violaciones, ¿qué? Cuántas veces él tuvo que sacar de su misma bolsa el dinero para que ella le echara tierra al asunto: "iDate de buenas que vas a tener un hijo güerito!”, les decía (Rulfo, 2005a: 110-11).

La frase "Lo asustado que estaba el Miguelito, aunque después le diera risa" expresa sintéticamente cómo se construye un sistema de creencias entre hombres que de modo implícito se están diciendo: "Esa gente no existe" (Pedro Páramo se encarga de hacer explícita esta proposición, con su lucidez y su poder): "lo asustado" señala el instante en que aún hay miedo, temor, prevención, vaga conciencia del daño causado; “después le diera risa" señala el momento en que la acción impune ha sido incorporada al sistema de creencias compartido; se ha incorporado gracias a la mutua convergencia de cinismos e intereses: la bestia humana es siempre más de una persona.

Sin duda, la reparación del daño es un tema que involucra las emociones y no únicamente las argumentaciones explícitas, por ejemplo las disquisiciones e interpretaciones legales. Por cierto, la reparación del daño emocional es un asunto sobre el que aún podría desplegarse más de una elucubración. Estos pasajes de Pedro Páramo servirían como un ejemplo y un estímulo.

El vínculo entre las emociones y la cuantificación de las mismas se encuentra en otro pasaje célebre de la novela, cuando ya en la tumba Dorotea le dice a Juan Preciado que mejor no hubiera salido de su tierra: 
- [...] ¿Qué viniste a hacer aquí?

-Ya te lo dije en un principio. Vine a buscar a Pedro Páramo, que según parece fue mi padre. Me trajo la ilusión.

- ¿La ilusión? Eso cuesta caro. A mí me costó vivir más de lo debido. Pagué con eso la deuda de encontrar a mi hijo, que no fue, por decirlo así, sino una ilusión más; porque nunca tuve ningún hijo. Ahora que estoy muerta me he dado tiempo para pensar y enterarme de todo. [...] Lo llevaba conmigo adondequiera que iba, envuelto en mi rebozo, y de pronto lo perdí. En el Cielo me dijeron que se habían equivocado conmigo. [...] Uno de aquellos santos se me acercó y, sin decirme nada, hundió una de sus manos en mi estómago como si la hubiera hundido en un montón de cera. Al sacarla me enseñó algo así como una cáscara de nuez. "Esto prueba lo que te demuestra".

"Tú sabes cómo hablan raro allá arriba; pero se les entiende" (Rulfo, 2005a: 64-65).

"Cuesta caro", "costó”, "Pagué”: esta microhistoria comienza con marcas evidentes del vínculo entre una emoción muy específica y singular, la ilusión, y la cuantificación de la misma mediante el costo. Toda ella, la microhistoria, es una argumentación que además remata con una parodia muy seria de la argumentación: "Esto prueba lo que te demuestra". Un círculo vicioso, una permanente petición de principio es esta frase, pero se entiende, se capta y, más aun, se acepta. Por lo demás, en Rulfo, como en el Eupalinos o el arquitecto, de Paul Valéry, la eternidad es el tiempo de la comprensión, el tiempo que restituye el ámbito ontológico para la comprensión, así sea a costa de la falta de un cuerpo por donde el pensamiento entre y salga, tal y como lo dice Sócrates justo al principio del texto:

FEDRo: ¿Qué haces ahí, Sócrates? De harto tiempo acá te andaba buscando. Recorrí nuestra pálida mansión, y no hubo sitio en que por ti no preguntara. Y todas estas gentes te conocen, y nadie te había visto. ¿Por qué así te alejaste de las demás sombras y qué pensamiento recompuso tu alma desviada de las nuestras, en los últimos hitos de este imperio transparente?

Sócrates: Espera. No acierto a responderte. Bien sabes que la reflexión es en los muertos indivisible. Estamos ya demasiado simplificados para no sufrir hasta su término el movimiento de las ideas que fuere. Permite su cuerpo a los vivientes salir del conocimiento y reingresar en él. Están compuestos de una casa más una abeja (Valéry, 1939: 3). 
La ilusión, en fin, es un buen ejemplo de una de las hipótesis centrales en el libro de Hansberg (2001): la de que las emociones se vinculan con actitudes proposicionales, esto es, con ideas, prejuicios, argumentaciones, hábitos (en el sentido de Pierre Bourdieu: habitus), visiones del mundo, etcétera. La ilusión es, en la psique de Juan Preciado, una construcción en parte intelectual, en parte inconsciente, en parte susceptible de expresarse mediante una explicación, en parte susceptible de esbozarse con una imagen o una figura más o menos vaga.

De hecho, todos estos pasajes son representativos de la novela, en tanto que hay en ella una permanente presencia de cargas emotivas, matizadas por elementos tales como la cuantificación de las mismas. Esta cuantificación es sorprendente, aunque ya el investigador español Ángel Alzaga (2010) ha descubierto que en el seminario de Guadalajara un Rulfo casi niño recibió una formación basada en principios del Concilio de Trento; estos principios apuntan a la cuantificación tanto de las culpas y de los pecados como de las indulgencias y las penitencias para subsanar el daño espiritual, si no es que físico ${ }^{13}$.

En todo caso, estamos aquí ante un ejemplo del tipo de giros que vuelven excepcional la narrativa de Rulfo: pocos enfoques o perspectivas hay tan comunes en la literatura como la emotividad. Dentro de la emotividad, el amor ocupa un sitio preponderante. Dentro del amor, el amor materno ha sufrido todos los desgastes propios de un tránsito de la literatura al cine de barrio y del cine de barrio a la telenovela. Pues bien, Rulfo alcanza aquí una tercera variación en una imagen que le resulta importante: precisamente la del progenitor que carga al vástago. En "Un pedazo de noche" (Rulfo, 2017) la variante consiste en que un sustituto de padre y de madre carga a una criatura de brazos por calles non sanctas de la ciudad. En "No oyes ladrar los perros" (Rulfo, 2005b) consiste en un padre viejo que se

${ }_{13}$ "Cuando Rulfo ingresa en 1932 en el seminario menor de Guadalajara, en el que permanecerá hasta 1934, son este tipo de textos los que circulan en aquel momento" (88). Se trata de textos donde "aparece la idea de un status intermedius que con posterioridad se teoriza bajo el concepto de evo (aevum) o eviternidad. Esta situación del alma separada, pero destinada necesariamente a un cuerpo por el que clama por unirse para restablecer la unidad sustancial (forma), lleva una existencia que ni transcurre en la eternidad ni forma parte del tiempo" (Alzaga, 2010: 87). 
echa al hijo adulto sobre los hombros. En Pedro Páramo, consiste en el deambular de la loca del pueblo (personaje típico o tópico) que tiene un hijo imaginario. Las tres variantes impiden desde un principio que el lector experimente una emoción convencional, pero la emoción de cualquier modo se produce (simpatía irónica en el primero y el tercero, compasión y espanto en el segundo), además de que en los tres casos los personajes argumentan (discuten, explican, acaso justifican) y así colocan su emoción en un campo argumentativo, en un sistema de proposiciones. De ese modo, se confirma que el texto literario proporciona dos niveles distintos en todos los aspectos, específicamente el del trenzado y entrecruzamiento de las argumentaciones y las emociones: uno es el nivel interno, entre los personajes, y otro es el nivel interno-externo (o intermedio entre el mundo posible del texto y el mundo fáctico de la vida), entre el autor implícito y el lector implícito.

Por último, la relación de Pedro Páramo con Bartolomé San Juan es un ejemplo de cómo se entremezclan cálculos muy fríos y emociones o afecciones y sentimientos. Un diálogo entre ambos determina el desenlace y acaba por echar las suertes de Comala y de la Media Luna. El diálogo no se narra directamente. Más bien, es un diálogo dentro de otro diálogo, ya que Bartolomé lo refiere y sintetiza delante de Susana.

- Hay pueblos que saben a desdicha. Se les conoce con sorber un poco de su aire viejo y entumido, pobre y flaco como todo lo viejo. Éste es uno de esos pueblos, Susana.

[...]

"Él nos ha pedido que volvamos. Nos ha prestado su casa. Nos ha dado todo lo que podamos necesitar. Pero no debemos estarle agradecidos. Somos infortunados por estar aquí porque aquí no tendremos salvación ninguna. Lo presiento.

“¿Sabes qué me ha pedido Pedro Páramo? Yo ya me imaginaba que esto que nos daba no era gratuito. $Y$ estaba dispuesto a que se cobrara con mi trabajo, ya que teníamos que pagar de algún modo. Le detallé todo lo referente a La Andrómeda y le hice ver que aquello tenía posibilidades, trabajándola con método. ¿Y sabes qué me contestó? 'No me interesa su mina, Bartolomé San Juan. Lo único que quiero de usted es a su hija. Ése ha sido su mejor trabajo'.

[...]". 
Bartolomé San Juan, un minero muerto. Susana San Juan, hija de un minero muerto en las minas de La Andrómeda. Veía claro. "Tendré que ir allá a morir”, pensó (Rulfo, 2005a: 88-89).

Pedro Páramo extrema aquí su bipolaridad de hombre de poder: no acepta una transacción por completo racional, para la cual Bartolomé ofrece lo único que posee: su fuerza de trabajo y su experiencia, su conocimiento y su planeación (habla incluso de "método", de una forma que hubiera complacido al propio Descartes). Carece de lo otro que hubiera necesitado: capital propio, así sea el mínimo indispensable para arrancar la empresa. Intentó conseguirlo profanando tumbas (entierros con ollas de oro, según viejos ritos) y, peor aun, obligando a Susana niña a descender a las tumbas a fin de obtenerlo. Pedro Páramo se burla de él usando la misma palabra, "trabajo", que Bartolomé empleó de modo racional instrumental. Y la remite al otro polo de su propia personalidad: Susana y el amor que siente por ella. Y es así como Páramo tiende un puente entre ambas mitades de su bipolaridad. Pero es un puente falso, desde el momento en que él ha decidido asesinar a su suegro. Bartolomé lo sabe: "Veía claro". Susana también lo sabrá: "Te asombrarías. Te digo que te asombrarías de oír lo que yo oigo" (Rulfo, 2005a: 116). Esta expresión parece sugerir que ha escuchado todo, incluso la orden de Pedro de asesinar a Bartolomé.

En todo caso, Susana se refugia en el silencio y coloca a Pedro en la peor de las situaciones frente a la persona amada: puesto que no se puede conocer el interior de las otras personas, los pensamientos más íntimos, el caudaloso flujo de la conciencia, entonces no queda sino 1) conjeturar lo que piensa la otra persona y 2) establecer pactos precarios con esa otra persona, sobre la base de la mutua confianza. Si Susana y Pedro hubieran sido personajes de Robert Musil, habrían discutido hasta el punto de acercarse a una cierta comprensión de los matices de sus sentimientos. Pero no hay personajes de Der Mann ohne Eigenschaften ni en la obra de Rulfo ni en la vida diaria: no podemos dedicarnos a discutir tranquilamente sobre cada uno de nuestros sentimientos, afecciones, pulsiones, pasiones. La vida nos está empujando todo el tiempo. Nos empuja hacia ella misma y hacia la muerte. No somos tampoco los personajes de Eupalinos de Valéry. Aún tenemos un cuerpo que nos distrae del pensamiento y que en cambio nos 
impulsa constantemente hacia esas emociones que más de una vez debemos matizar con algunos pensamientos.

\section{Referencias}

Alzaga, Á. (2010). 'Ya de por sí la vida se lleva con trabajo'. Reflexiones en torno a algunos componentes religiosos de la novela Pedro Páramo. En A. M. Ejdesgaard Jeppesen (coord.), Tras los murmullos. Lecturas mexicanas y escandinavas de Pedro Páramo (pp. 87-100). Copenhagen: Museum Tusculanum Press.

Bartra, R. (2004). La conciencia y el exocerebro. Una hipótesis sobre los sistemas simbólicos de sustitución. Revista de la Universidad de México, 2, 59-65. Disponible en www.revistadelauniversidad.unam.mx.

. (2007). Antropología del cerebro. La conciencia y los sistemas simbólicos. Segunda edición. México: Fondo de Cultura Económica / Pre-textos.

Del Val, J. (2015). Palabras pronunciadas en la inauguración del 1er. Simposio Miradas Contemporáneas a la familia. Ciudad de México, 2 de diciembre.

Garrido Domínguez, A. (2007). El texto narrativo. Madrid: Síntesis.

Hansberg, O. (1996). De las emociones morales. Revista de Filosofía, 3 a época, IX (16), 151-170.

. (2001). La diversidad de las emociones. México: Fondo de Cultura Económica.

Jauss, H. R. (1982). Literarische Hermeneutik und Ästhetische Erfahrung. Frankfurt: Suhrkamp.

Lechner, N. (2002). Las sombras del mañana. La dimensión subjetiva de la política. Santiago: Lom ediciones.

Nussbaum, M. C. (2008). Paisajes del pensamiento. La inteligencia de las emociones. Trad. de A. Maira. Barcelona / Buenos Aires / México: Paidós.

Rulfo, J. (2005a). Pedro Páramo. México: RM / Fundación Juan Rulfo. . (2005b). No oyes ladrar los perros. En El llano en llamas (pp. 129-134). México: RM / Fundación Juan Rulfo. . (2017). Un pedazo de noche. En J. C. González Boixo y D. Weatherford (ed., intr.), D. Brennan (nota y fijación de "La fórmula secreta"), El gallo de oro y otros relatos (pp. 133-142). México: RM / Fundación Juan Rulfo.

Shakespeare, W. (1996). The complete works of William Shakespeare. Londres: Wordsworth.

Valéry, P. (1939). Eupalinos o el arquitecto. Trad. de M. Pani. Ciudad de México: Cultura.

Vital Díaz, A. (2017). Los argumentos de los asesinos. Mecanismos de justificación en personajes de Juan Rulfo. Ciudad de México: Universidad Nacional Autónoma de México. 